\title{
Maturity and Change in Personality: Developmental Trends of Temperament and Character in Adulthood
}

\section{Josefsson, Kim}

2013

Josefsson , K, Jokela , M , Cloninger , R, Hintsanen, M , Salo , J , Hintsa , T , Pulkki-Råback , L \& Keltikangas-Järvinen , L 2013 , ' Maturity and Change in Personality:

Developmental Trends of Temperament and Character in Adulthood ' , Development and Psychopathology , vol. 25 , no. 3 , pp. 713-727 . https://doi.org/10.1017/S0954579413000126

http://hdl.handle.net/10138/40251

https://doi.org/10.1017/S0954579413000126

acceptedVersion

Downloaded from Helda, University of Helsinki institutional repository.

This is an electronic reprint of the original article.

This reprint may differ from the original in pagination and typographic detail.

Please cite the original version. 
Running head: DEVELOPMENTAL TRENDS OF TEMPERAMENT AND

\section{CHARACTER}

Maturity and Change in Personality: Developmental Trends of Temperament and

\section{Character in Adulthood}

Kim Josefsson

IBS, Unit of Personality, Work, and Health Psychology, University of Helsinki,

Finland

Finnish Institute of Occupational Health, Finland

Markus Jokela

IBS, Unit of Personality, Work, and Health Psychology, University of Helsinki,

Finland

C. Robert Cloninger

Department of Psychiatry, Washington University School of Medicine, St. Louis Mirka Hintsanen

Helsinki Collegium for Advanced Studies, University of Helsinki, Finland IBS, Unit of Personality, Work, and Health Psychology, University of Helsinki,

Finland

Johanna Salo, and Taina Hintsa

IBS, Unit of Personality, Work, and Health Psychology, University of Helsinki,

Finland

Laura Pulkki-Råback

IBS, Unit of Personality, Work, and Health Psychology, University of Helsinki,

Finland

Finnish Institute of Occupational Health, Finland 
Liisa Keltikangas-Järvinen

IBS, Unit of Personality, Work, and Health Psychology, University of Helsinki,

Finland

Acknowledgements

This study was supported by Emil Aaltonen Foundation (MH), Niilo Helander Foundation (MH), Ella and Georg Ehrnrooth Foundation (TH and $\mathrm{MH})$, Finnish Foundation for Cardiovascular Research (MH), the Academy of Finland (grant 123621 to LP-R, grant 132729 to $\mathrm{TH}$, and grant 124399 to LK-J)

Corresponding author: Liisa Keltikangas-Järvinen, IBS, Psychology, University of Helsinki, Finland; Liisa Keltikangas-Järvinen, Siltavuorenpenger 1A, P.O.Box 9, 00014 University of Helsinki, Finland. Tel: +358 91912 9500, Fax: +358 91912 9251, email: liisa.keltikangas-jarvinen@helsinki.fi 
Maturity and Change in Personality: Developmental Trends of Temperament and Character in Adulthood

\begin{abstract}
We studied the developmental trends of temperament and character in a longitudinal population-based sample of Finnish men and women aged 20-45 years using the Temperament and Character Inventory (TCI) model of personality. Personality was assessed in 1997, 2001, and 2007 ( $n=2104,2095$, and 2056, respectively). Mean-level changes demonstrated qualitatively distinct developmental patterns for character (Self-directedness, Cooperativeness, Self-transcendence) and temperament (Novelty Seeking, Harm Avoidance, Reward Dependence, Persistence). Character developed towards greater maturity, although Self-transcendence decreased with age. However, Self-transcendence was the strongest predictor of overall personality change. Cohort effects indicated lower level of Selftranscendence and higher level of Self-directedness and Cooperativeness in younger birth cohorts. Regarding temperament, Novelty Seeking decreased and Persistence increased slightly with age. Both high Novelty Seeking and high Persistence predicted overall personality change. These findings suggest that temperament and character traits follow different kinds of developmental trajectories.
\end{abstract}

keywords: personality, change, temperament, character, human development, selfregulation 
The degree and direction of personality change in adulthood is a central topic in understanding human psychological development. Several personality theories have emphasized how adult personality tends to develop towards higher levels of psychological maturity (Caspi, Roberts, \& Shiner, 2005; Hopwood et al., 2011; Lucas \& Donnellan, 2011; McAdams \& Olson, 2010; Roberts, Wood, \& Caspi, 2008; Soto, John, Gosling, \& Potter, 2011). Maturity is a somewhat ambiguous concept that attempts to describe directions and end states of personality development that are psychologically healthier and more fulfilling than lower levels of psychological maturity. Developmental theories offer two different views on maturity (Caspi et al., 2005; Helson \& Wink, 1987; Hogan \& Roberts, 2004; Staudinger \& Kunzmann, 2005). The perspective of personal growth concentrates on concepts such as insight, integrity, and wisdom. Personal growth is seen as positive development that enables the individual to actualize his or her full potential as a person. The functional perspective, on the other hand, equates maturity with adjustment to the society, that is, being a productive contributor to the society and being respected and liked by other people.

\section{Maturity and psychological well-being}

Gordon Allport (Allport, 1961) used six criteria to give maturity (or healthy personality) a definition that, in his words, was a balance between too fine and too coarse distinctions. The first criterion is self-extension which was defined as authentic participation by the person in some significant spheres of human endeavor, such as work, family-life, or politics. The second criterion is the ability to relate oneself warmly to others in both intimate (love) and non-intimate (compassion) contacts. The third criterion is emotional security or selfacceptance, that is, a skill to live with one's emotional states. The fourth criterion is realistic perception, thinking, and appraisals, that is, seeing the world as it is and not bending the reality to fit one's needs. The fifth criterion is insight and humor, that is, knowing oneself and 
being able to laugh at oneself. The sixth and final criterion is a unifying philosophy of life, that is, a clear comprehension of the purpose of one's life.

Based on the work of Allport and others and the literature on positive functioning, Carol Ryff introduced a model of psychological well-being that also consists of six dimensions (Ryff, 1989; Ryff \& Keyes, 1995). These dimensions are self-acceptance (positive evaluations of oneself and one's past life), personal growth (sense of continued development and growth as a person), purpose in life (meaningful life), positive relations with others, environmental mastery (being able to manage effectively one's life and the surrounding world), and autonomy (sense of self-determination).

More recently, Hogan and Roberts (Hogan \& Roberts, 2004) introduced a socioanalytic model of maturity. According to the model, it is important to distinguish between how people see themselves and how others see them; maturity is defined from both the actor's and the observer's perspective. Maturity is divided into identity elements (selfacceptance and being attentive and responsive to others' needs, expectations, and feelings) and reputational elements (being liked and respected by others). These elements of maturity are associated with success in different roles such as marital stability and career success (Hogan \& Roberts, 2004).

\section{Mean-level change of personality}

Perhaps the most intensively studied modern personality trait taxonomy in relation to personality change is the Big Five. Previous cross-sectional and longitudinal studies have shown that agreeableness, conscientiousness, emotional stability and social dominance (e.g., social self-confidence) increase from young adulthood to middle-age (Lucas \& Donnellan, 2011; Luedtke, Roberts, Trautwein, \& Nagy, 2011; McAdams \& Olson, 2010; Roberts, Walton, \& Viechtbauer, 2006; Soto et al., 2011). McAdams and Olson (McAdams \& Olson, 
2010) summed up these findings by stating that "by middle-age, people appear to become more comfortable with themselves as adults, less inclined to moodiness and negative emotions, more responsible and caring, more focused on long-term tasks and plans, and less susceptible to extreme risk-taking and the expression of unbridled internal impulses". This developmental pattern has also been described as following the "maturity principle", which implies that people become more mature with age (Caspi et al., 2005).

There are also some cross-sectional studies that have reported age-related differences in dimensions of psychological well-being (Ryff, 1989; Ryff, 1991; Ryff \& Keyes, 1995). Environmental mastery and autonomy increase with age in adulthood, whereas purpose in life and personal growth decrease. Self-acceptance and positive relations with others usually show no age related differences. Thus the different facets of psychological wellbeing do not uniformly increase with age in a way that allows psychological well-being to be equated with maturity of personality.

\section{Rank-order stability of individual differences in personality}

It is important to distinguish between mean-level personality change, which evaluates how individuals develop over time on average, and rank-order personality change, which is concerned with change in the relative position of individuals on a certain trait over time (Caspi et al., 2005). Mean-level change coupled with high rank-order stability implies that the observed mean-level change is due to normative (i.e, norm-favoring) change in personality (Klimstra, Hale, Raaijmakers, Branje, \& Meeus, 2009). Normative change often occurs to a similar degree in most people in the population.

Previous research suggests that rank-order stability increases with age, indicating that people are less likely to change in respect to others when they become older, and decreases with longer time intervals between the two measurements (Lucas \& Donnellan, 2011). One 
meta-analysis estimated that the rank order stability of personality characteristics increases from .5 to about .6 from early adulthood to middle-age, when the time-interval is about 7 years (Roberts \& DelVecchio, 2000). A more recent meta-analysis reported increasing rankorder stability from .6 in early adulthood to about .7 in middle-age with about 7-year time intervals (Ferguson, 2010). In a study of Big Five traits in adults aged 30 or older with an average follow-up interval of ten years, rank-order stability coefficients were all around .8 (Terracciano, Costa, \& McCrae, 2006). A more recent study using only the Big Five traits, a four-year measurement interval, and a wide age-range found that rank-order stability ranged from .64 to .73 (Specht, Egloff, \& Schmukle, 2011). Thus, there is some variation in the estimates of rank-order stability between different studies, which may be explained by differences in the length of the time interval and the reliability of the measurement scales.

\section{The psychobiological theory of personality}

The psychobiological theory of personality (Cloninger, 2008) postulates that personality is composed of temperament and character, two inter-related domains which are hypothesized to interact as a non-linear dynamic system regulating the development of human psychological functions. Temperament traits become manifest early in life and reflect biases in automatic responses to emotional stimuli, whereas character traits depict differences in higher cognitive functions underlying a person's goals and values (Cloninger, Svrakic, \& Przybeck, 1993). Temperament involves involuntary emotional processes, whereas character involves voluntary rational processes (Cloninger, 2008). Temperament and character are considered to interact dynamically in the development of personality across the lifespan (Cloninger, Svrakic, \& Svrakic, 1997; Cloninger, 2008).

Originally, the temperament domain of the psychobiological model consisted of three dimensions, which were proposed to be independently heritable (Cloninger, 1987). These 
dimensions were Novelty Seeking (a bias towards initiation of behaviors, like exploratory activity in response to novelty), Harm Avoidance (a bias to respond intensely to aversive stimuli and to inhibit behaviors), and Reward Dependence (a tendency to respond intensely to social approval) (Cloninger, 1987). A fourth temperament dimension, Persistence (perseverance despite frustration and fatigue), was later distinguished from Reward Dependence because it was found to be independently heritable (Cloninger et al., 1993; Heath, Cloninger, \& Martin, 1994; Stallings, Hewitt, Cloninger, Heath, \& Eaves, 1996). According to the theory (Cloninger et al., 1993), the three character dimensions assessed by the Temperament and Character Inventory (TCI) are Self-directedness, Cooperativeness and Self-transcendence, and they reflect three different aspects of a person's self-concept and object relations. Self-directedness is the extent to which a person identifies the self as an autonomous individual. Cooperativeness expresses empathy and identification with other people, and Self-transcendence involves self-awareness of being an integral part of the unity of all things. The temperament traits reflect basic stimulus-response characteristics underlying basic emotions of anxiety, anger, attachment, and ambition, whereas character dimensions aim at depicting the maturity and coherent integration of the multiple facets of each individual's personality in pursuit of particular goals and values over his or her lifespan.

In the psychobiological theory, maturity refers to the character configuration typical of healthy middle-aged individuals, which is characterized by high self-directedness and high cooperativeness (Cloninger et al., 1997; Cloninger et al., 1993; Cloninger \& Zohar, 2011; Josefsson et al., 2011). Extreme immaturity, on the other hand, is often related to diagnosable personality disorders (Cloninger, 2010; Svrakic, Whitehead, Przybeck, \& Cloninger, 1993), and extreme temperament variants may differentiate between various subtypes of personality disorder (Cloninger, 1987). 
Character is assumed to develop in adulthood as a result of conceptual learning of the meaning and consequences of one's actions (Cloninger et al., 1993). However, individual differences in the character traits are as heritable as the temperament traits (Gillespie, Cloninger, Heath, \& Martin, 2003), suggesting that the division between temperament and character cannot be made simply on the basis of more and less heritable components of personality. The division is also not supported by factor analysis studies that have reported substantial cross-loadings across the temperament and character traits (Farmer \& Goldberg, 2008b; Herbst, Zonderman, McCrae, \& Costa, 2000; Maitland, Nyberg, Bäckman, Nilsson, \& Adolfsson, 2009). These results seem to suggest that character and temperament do not represent psychologically separate domains. However, other researchers have argued that it is quite possible for two moderately correlated traits to represent psychologically distinct constructs (Block, 1995). Other methodological approaches besides factor analysis need to be applied to assess the differences and similarities between temperament and character traits.

\section{Stability and change of temperament and character}

Previous research on the stability and change of the TCI traits in adulthood is sparse. Assuming that psychological maturity increases with age and that character traits reflect the degree of personality maturity, one would expect Self-directedness and Cooperativeness, in particular, to increase with age. Research on character traits has shown that increasing age is strongly correlated with Self-directedness and Cooperativeness, but not Self-transcendence by age 35 or 40 years in most cultures (Cloninger et al., 1993). However, the evidence is contradictory with some studies providing empirical support for increasing levels of character traits (Cloninger et al., 1997; Cloninger, 2003; Cloninger et al., 1993) and some not (Farmer \& Goldberg, 2008a). Novelty Seeking appears to decrease with age while no 
consistent age-related change has been reported for other temperament dimensions (Cloninger, 2003; Cloninger et al., 1993; Trouillet \& Gana, 2008).

These findings derive from cross-sectional study designs, so the evidence of agerelated development of temperament and character traits remains limited (Cloninger, 2003; Cloninger et al., 1993; Trouillet \& Gana, 2008). Cross-sectional data which may not be able to capture true aging effects due to confounding effects of birth cohort differences, which is why longitudinal studies with sufficiently long follow-up spans are needed to assess developmental trajectories in temperament and character. One longitudinal study with two assessments one year apart provided support for the cross-sectional results (Cloninger et al., 1997). However, there have been no long-term longitudinal studies with follow-up more than one year or longitudinal studies in other countries besides the United States.

Regarding rank-order correlations assessing the stability of individual differences over time, short-term (one to two weeks) test-retest correlations of the revised TCI-traits have been shown to range from .81 to .94 (Hansenne, Delhez, \& Cloninger, 2005; Pelissolo et al., 2005), indicating high reliability of the traits. A study with a six-month follow-up reported correlations between .68 and .88 (Martinotti et al., 2008). In a one-year longitudinal study, correlations of the TCI-traits were between .78 and .85 (Cloninger, Svrakic, \& Przybeck, 2006). A study with an average retest interval of 2 years reported correlations of $.68-.82$ for the temperament traits (Gillespie et al., 2003). As there have not been many longitudinal studies concentrating on the stability of the TCI-traits, the evidence regarding the rank-order stability of the TCI-traits is limited.

\section{Present study}

The purpose of the present study was to examine the developmental patterns of the TCI-traits in a large population-based longitudinal study. First, we assessed rank-order 
stability and mean-level changes of the TCI-traits over a 10-year time-span. Our second aim was to relate the observed developmental patterns to the concept of maturity; we examined whether the level of maturity is associated with the degree and direction of personality change, and whether the personality change patterns of the TCI can be understood as people becoming more mature with age.

The psychobiological theory postulates that temperament traits are stable over time or show mixtures of small increases or decreases with no systematic directional bias in behavioral conditioning from unique individual experiences (Cloninger, 2004). Both high and low extremes of each temperament can be advantageous or disadvantageous depending on the situational context (Cloninger, 1987; Jokela, Hintsa, Hintsanen, \& Keltikangas-Jarvinen, 2010). Behavioral conditioning of individuals is expected to have little or no effect on the average levels of temperament traits in the population which leads to roughly equal numbers of people developing higher or lower scores on each trait.

By contrast, character traits are expected to be stable or to develop towards greater maturity with age due to socio-cultural learning and increasing self-awareness and foresight about long-term consequences of voluntary behavioral choices (Cloninger et al., 1997; Cloninger et al., 1993). Self-directedness and Cooperativeness are often perceived as socially desirable and to reflect psychological maturity, which may facilitate their development (e.g., Andersson, 2008; Ojala, 2000). Some form of spirituality and connectedness with the world is also often perceived as a sign of maturity (Allport, 1951; Cloninger, 2004). Selftranscendence may thus increase over time because it is associated with greater positive emotion, although such changes may take place only after middle age (Cloninger, 2004). However, in modern secular cultures, such as that in Finland, more skeptical, rationalistic, and non-spiritual perceptions of the world are often prevalent and valued (Kääriäinen, Ketola, Niemelä, Palmu, \& Salomäki, 2009). This may be observed as decreasing Self-transcendence 
with age as a result of internalization of secular norms. As a result of such systematic directional bias from social norm-favoring, the effect size of change in character traits is expected to be higher for character traits than for temperament traits.

Based on previous research (Caspi et al., 2005; Roberts, Caspi, \& Moffitt, 2001) and the theoretical considerations presented above, we hypothesize that the mean-levels of the TCI-traits show evidence of increased maturity with age (i.e., the average levels of the character traits have a strong positive developmental direction when comparing people grouped by age whereas the group averages of temperament traits do not change much with age). Concerning the rank-order correlations, we expect the TCI stability coefficients to be about the same magnitude as the coefficients reported for the Big Five since both represent modern and comprehensive personality inventories comprised of traits with complex but strong correlations across inventories (Cloninger, 2006). Third, we examine whether initial levels of temperament and character traits can be used to predict the magnitude of personality change over time. Previous research suggests that mature people change less with age than relatively immature people (Caspi et al., 2005; McAdams \& Olson, 2010; Roberts et al., 2001).

\section{Method}

\section{Participants}

The participants were from the Young Finns study. In this population-based epidemiological study a randomly selected sample of 3596 participants has been followed for 27 years in eight follow-up phases between 1980 and 2007. The sample consists of six birth cohorts aged 3 to 18 at baseline in 1980 . The design of the study and the selection of the sample have been described in detail elsewhere (Raitakari et al., 2008). The measurements for the present study were carried out in 1997, 2001 and 2007. In 1997 the participants were 
20, 23, 26, 29, 32 and 35 years old. Both temperament and character traits were assessed in 1997 and 2001, but only the temperament traits were assessed in 2007 due to space limitations of the questionnaire. All participants with full data in at least one of the years 1997, 2001, and 2007 were included in the study. Trait scores were calculated for participants if they had answered at least $50 \%$ of the trait items. Full data were available for 2104 participants in 1997, 2095 participants in 2001, and 2056 participants in 2007. Of these participants $98.4 \%, 98.9 \%$, and $99.9 \%$ had at most two missing items per trait in years 1997 , 2001, and 2007, respectively.

Assessment of Cloninger's temperament and character traits

We used version 9 of the TCI which has 240 items (C. R. Cloninger, Przybeck, Svrakic, \& Wetzel, 1994). Instead of the original true / false response format, we used a 5 point Likert-scale with response categories ranging from 1) definitely false to 5) definitely true. Temperament dimensions include Harm Avoidance (HA; 35 items, Cronbach's $\alpha=0.92$ ), Novelty Seeking (NS; 40 items, $\alpha=0.85$ ), Reward Dependence (RD; 24 items, $\alpha=0.80$ ) and Persistence (PS; 8 items, $\alpha=0.64$ ). Character dimensions include Self-directedness (SD; 44 items, $\alpha=0.89$ ), Cooperativeness (CO; 42 items, $\alpha=0.91)$ and Self-transcendence (ST; 33 items, $\alpha=0.91)$.

\section{Statistical analyses}

Means and standard deviations at different follow-up examinations were calculated separately for men and women. Possible gender by measurement year interactions were tested using mixed measures ANOVA. None of the gender by measurement year interactions were significant, so the analyses were fitted with men and women combined. 
When exploring mean-level stability and change of the TCI traits, participants were divided into 5-year age groups. This resulted in five age groups for temperament $(20-24,25-$ $29,30-34,35-39$ and 40-45 years) and four for character (20-24, 25-29, 30-34 and 35-39 years). In order to examine longitudinal and within-individual associations, the repeated measurements were pooled into a multilevel format in which measurements were nested within participants. The associations were analyzed with a multilevel linear model (generalized estimating equations with unstructured error structure). Age was modeled both as a categorical and continuous variable. To assess aging effects within individuals, we fitted regression models with both within-individual and between-individual associations with the model: $\mathrm{Y}=\mathrm{B}_{0}+\mathrm{B}_{\mathrm{W}}\left(\mathrm{X}-\mathrm{X}_{\mathrm{M}}\right)+\mathrm{B}_{\mathrm{B}} \mathrm{X}_{\mathrm{M}}($ Carlin, Gurrin, Sterne, Morley, \& Dwyer, 2005), where $\mathrm{Y}=$ trait score, $\mathrm{B}_{0}=$ intercept, $\mathrm{B}_{\mathrm{W}}=$ within-individual coefficient, $\mathrm{X}=$ participant's time-varying age, $X_{M}=$ participant's mean age across all measurements, $B_{B}=$ between individuals coefficient. Here the within-individual coefficient is the association of interest, because it reflects an aging effect within individuals that is not confounded by stable differences between individuals (e.g., cohort effects). To facilitate interpretation of effect sizes, all temperament and character traits were standardized using the mean and standard deviation of the 20-year old group as the reference.

The hypothesis of personality maturity being associated with lesser personality change was assessed between the 1997 and 2001 measurements. The degree of personality change was defined as Euclidean distance between personality trait-scores in 1997 and in 2001 (standardized to the mean and standard deviation of the traits in 1997). The distance was calculated separately for a) character traits, b) temperament traits, and c) character and temperament combined. Euclidean distance in seven-dimensional TCI personality space

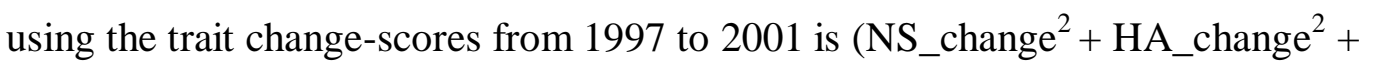
$R D \_$change $e^{2}+P S \_c h a n g e^{2}+S D \_c h a n g e^{2}+C O \_c h a n g e^{2}+S T \_$change $\left.^{2}\right)^{1 / 2}$. 


\section{Results}

\section{Descriptive statistics}

Table 1 presents means and standard deviations of TCI traits in men and women. Women scored higher than men in Novelty Seeking, Harm Avoidance, Reward Dependence, Cooperativeness and Self-transcendence in all measurement years. There was no statistical difference in the mean-levels of Self-directedness or Persistence between men and women. The only gender difference greater than half a standard deviation was for Reward Dependence, which is higher in women.

Table 1 about here

\section{Rank-order correlations over time}

Table 2 shows the correlation of the TCItraits over 4, 6, and 10 years. Except for persistence, both temperament and character had rather high correlations of $>.70$. Furthermore, the 10 year correlations of temperament were comparable in magnitude to that of shorter timeintervals, suggesting little attenuation with the lengthening of the time interval. There was a clear increasing trend in the correlation coefficients with age; correlations in the age group 29-35 were higher than in the age group 20-26 in almost all the comparisons, although the age-group differences were statistically significant only for Novelty Seeking and Harm Avoidance.

Table 2 about here

Mean-level stability and change

Stability and change in temperament. Figure 1 shows the development of temperament scores by age group. Of the four temperament traits, Novelty Seeking showed 
most evidence of change over time. Novelty Seeking was rather stable between age groups 20-24 and 25-29 but decreased steadily after that. By age 40-44 years Novelty Seeking showed a decrease of 0.4 standard deviations. Harm Avoidance stayed stable over time and did not show any significant directional change. Reward Dependence showed a slight decreasing linear trend with age with a decrease of 0.2 standard deviations by the age of 40 44 years. Persistence showed a slight increasing trend with age $(0.1-0.2$ standard deviations by the age of 40-44 years). Table 3 shows that within- and between-individuals change coefficients were almost equal for Novelty Seeking, Harm Avoidance, and Reward Dependence, suggesting that the total regression coefficient was not substantially biased by factors other than age. For Persistence the within individuals coefficient was somewhat higher than the between individuals coefficient. These results are supported by the actual cohort differences shown in Table 4.

Figure 1 and Table 3 about here

Stability and change in character. Figure 2 shows the development of character scores with age. All three character traits showed evidence of change with age. Interestingly, controlling for the birth year increased the mean-score estimates of the three character traits substantially. Self-directedness, and Cooperativeness increased strongly with age with an increase of 0.7 and 0.4 standard deviations by the age $35-39$ years, respectively. Selftranscendence showed a decrease of 0.7 standard deviations by the age 35-39 years. Using age as a continuous variable revealed marked differences between the within-individual and between-individual regression coefficients (Table 3), suggesting that the total regression coefficients underestimated the true aging effects revealed by within-individual associations. Adjusting for birth year amplified the age effects substantially because younger birth cohorts had higher Self-directedness, higher Cooperativeness, and lower Self-transcendence than the older birth cohorts (Table 4). 
Figure 2 about here

Temperament vs. character. There are differences between temperament and character traits as can be seen in Figures 1 and 2, and Table 3. All three character traits changed more with age than any of the temperament traits. In addition, birth year had a strong effect on the mean-level of the character traits but not on the mean-level of the temperament traits.

\section{TCI-traits predicting personality change}

Table 5 shows the standardized mean-scores of the TCI-traits in year 1997 predicting total personality change (a positive coefficient indicating that people high on a given trait change more and a negative one indicating that people high on a given trait change less) from year 1997 to 2001. Harm Avoidance and Reward Dependence did not predict overall personality change. High Novelty Seeking, high Persistence and high Self-transcendence predicted consistently larger overall change in personality. The largest change in total personality was predicted by high Self-transcendence. Cooperativeness predicted overall change in character traits; low Cooperativeness predicted larger change in character. Selfdirectedness did not predict overall change in temperament but it did predict change in character and combined temperament and character; low Self-directedness predicts larger change in combined temperament and character and in character.

Table 5 about here

\section{Discussion}

Our findings show that the rank-order stability of the TCI-traits is fairly high and is very similar in magnitude for the temperament and the character traits, implying that individuals are likely to retain their relative ranking compared to other individuals over several years. 
Concerning mean-level changes with age, temperament traits measuring basic emotional response biases changed less than character traits that are suggested to appear later in development. Also, there were no substantial birth-year effects in temperament traits but younger birth cohorts had higher Self-directedness, higher Cooperativeness, and lower Selftranscendence than older birth cohorts. Finally, people high on Novelty Seeking, Persistence, Self-directedness, Cooperativeness, or Self-transcendence showed more personality change over time than people low on these traits, providing mixed evidence for the hypothesis that mature personality is less likely to change than immature personality.

\section{Rank-order stability of temperament and character}

Temperament and character traits did not differ substantially in the stability of individual differences over time. In agreement with previous literature showing increasing rank-order stability with age, the stability correlations for Novelty Seeking and Harm Avoidance were slightly higher for the 29-35-year age group compared to the 20-26-year age group. However, the differences were modest and not observed for other traits. The increasing rank-order stability may be observed more clearly in older ages than the 20 to 35 years covered in the present study. The ten-year rank-order stability coefficients were all smaller in magnitude than the four or six year coefficients, which is in agreement with the general pattern of decreasing stability with increasing length of follow-up (Lucas \& Donnellan, 2011). The rank-order stability coefficients in the present study are somewhat higher than in previous studies (Cloninger et al., 2006; Ferguson, 2010; Gillespie et al., 2003; Roberts \& DelVecchio, 2000) but not exceptionally high (Terracciano et al., 2006). 
Even though temperament and character have substantial unique genetic variance, they are equally heritable (Gillespie et al., 2003) and correlate moderately with each other, which has challenged the assumption that they represent qualitatively different domains of personality. The mean-level changes of all the three character traits showed clear and consistent agerelated trends with effect sizes larger than the trends observed for any of the four temperament traits. The effect sizes measured by standard deviation (Figure 2) were large for Self-directedness (positive age trend, +) and Self-transcendence (negative age trend, -) and rather large also for Cooperativeness (+). The effect sizes for temperament traits (Figure 1) were moderate for Novelty Seeking (-), weak for Persistence (+) and Reward Dependence (-), and near zero for Harm Avoidance. Interestingly, birth year effects had no or only little relevance in these developmental trajectories of temperament traits but marked birth-year effects were observed for character traits. Older cohorts were less self-directed, less cooperative, and more self-transcendent than younger cohorts. Thus, character traits appear to be more sensitive than temperament traits to both aging effects and to differences in societal and historical factors that characterize the society in different points in time. Despite the moderately high correlations between, say, Harm Avoidance and Self-directedness $(r=-.62$ in present study), our results suggest some clear differences between the domains of temperament and character.

\section{Mature personality from the perspective of temperament and character}

A good approximation of a person's level of maturity is the sum of Self-directedness and Cooperativeness scores (Cloninger, 2004) and the mean-levels of both SD and CO increased with age in our study sample. Having a mature personality makes it easier to regulate one's emotions responsibly and considerately; if one is anxiety-prone (high HA), impulsive (high NS) and mature (high SD and high CO) at the same time, maturity helps one to behave 
rationally in spite of experiencing emotional conflicts. According to this view, maturity is not related to the quality or intensity of emotions but to living a balanced life with awareness and understanding of one's emotions. At the same time, mature personality organization enhances work performance and helps also in other culturally valued tasks. In addition, both high and low extremes of each temperament can be advantageous or disadvantageous depending on the situational context (Cloninger et al., 1993). For example, being high on Persistence helps one to perform well in work despite disappointment, frustration, and fatigue. But at the same time, the perfectionistic nature of high Persistence might influence negatively one's marriage by predisposing a person to neglect their family for work, or alternatively to pursue an overly perfect relationship, children, and home (Cloninger, Zohar, Hirschmann, \& Dahan, in press ). So there is no one culturally preferred temperament profile. However, maturity of character is culturally preferred to immaturity of character because a mature character is advantageous in most life situations. The increasing trends of SD and CO are also in line with the Big Five related studies which have found increasing agreeableness and conscientiousness with age.

Our results imply that character profiles of Finnish people tend to develop from disorganized (low SD, low CO, high ST) to organized (high SD, high CO, low ST) by age 40. Disorganized character can be defined as unconventional behavior and also not setting realistic goals, thinking magically and not analytically, and not having emotionally rewarding and trusting relationships (Cloninger, Bayon, \& Svrakic, 1998). Disorganized people are illogical, suspicious, and immature while organized people are conservative, efficient and consistent. Organized people can reason analytically and are generally logical, trusting, and mature. Thus, character seems to develop towards greater maturity. Mature personality is often described as being a productive member of society, being organized and decisive in one's actions, and being considerate towards other people (Caspi et al., 2005). These qualities, among others, are measured by TCI character traits (Cloninger, 2008), which 
supports the proposal in DSM-V to define healthy personality functioning in terms of high Self-directedness and Cooperativeness (Cloninger, 2010).

On the other hand, immature character (i.e., low Self-directedness and low Cooperativeness) is typical of individuals with most forms of psychopathology, including mood disorders, schizophrenia, substance dependence, and personality disorders (Cloninger, Zohar, \& Cloninger, 2010). High Self-transcendence, in turn, is associated with both positive health and particular forms of psychopathology, such as schizophrenia and bulimia. Specific forms of psychopathology are associated with specific temperament traits, such as high Harm Avoidance with anxiety and mood disorders, high Novelty Seeking with substance dependence, low Reward Dependence with schizoid disorders, and high Persistence with obsessional disorders (Cloninger et al., 2010; Mulder \& Joyce, 1997). These observations illustrate the important role that maturation of character has in reducing vulnerability to psychopathology and provides further support for the distinction between temperament and character.

We found that a mature character at age 40 in Finland involves low Selftranscendence. As our cohorts age further, however, people will face more suffering and death, which may make an increase in Self-transcendence adaptive (Cloninger, 2004; Coward \& Reed, 1996). In cross-sectional studies, people over age 60 are higher in Selftranscendence than those at middle age or younger (Cloninger, 2003). Further work on the role of Self-transcendence in life satisfaction must examine the course of personality development prospectively and also examine interactions among all the personality dimensions with different aspects of health and happiness (Cloninger \& Zohar, 2011).

Although mean-level studies of personality traits show that people mature with age, some people change reliably in the opposite direction than the observed mean-level trends (Roberts, Wood, \& Smith, 2005). This is probably caused by individual experiences in 
people's lives (Roberts \& Mroczek, 2008). Some life-events, for example a divorce, might result in negative changes in personality if the event is interpreted to be relevant to one's identity (Lodi-Smith \& Roberts, 2007). What is critical is how important people see their social roles (e.g., work or marriage) to be, what kind of expectations they have for themselves, and what kind of expectations other people have for them (Roberts et al., 2005).

Predicting whose personality will change: the role of maturity

The present study also addressed the hypothesis of psychological maturity and degree of subsequent personality change (Roberts et al., 2001). High Novelty Seeking, high Persistence, low Self-directedness, low Cooperativeness, and high Self-transcendence predicted greater personality change over four years. People with a preference for novelty seek out new experiences, people, and environments. Consequently, there is less stability in their environments, and this instability is probably the driving force behind the personality change of novelty seekers. The effect of Persistence can probably be explained by sustained effort which is required for personality change to take place.

Character traits of people low on Self-directedness, low on Cooperativeness, or high on Self-transcendence were more likely to change over time than were those high on Selfdirectedness, high on Cooperativeness, or low on Self-transcendence (Table 5). It seems that immature people (low SD and low $\mathrm{CO}$ ) are more prone to personality change than mature people, which is in line with previous studies (Caspi et al., 2005; Donnellan, Conger, \& Burzette, 2007; McAdams \& Olson, 2010; Roberts et al., 2001). Mature people receive less pressure than immature people from society to change in a norm-favored direction since they already are near the cultural norm. Mature people are also less likely to face important lifechanging decisions since they have usually already chosen their path in life (Donnellan et al., 2007). Maturity might also facilitate the development of resilience to environmental 
adversity and improve coping in challenging life situations (Caspi et al., 2005). Furthermore, universal social roles related to work, family and community in general may explain the observed maturation trend (Donnellan \& Trzesniewski, 2010; Roberts \& Mroczek, 2008). This explanation is further strengthened by the fact that there are no known human cultures that avoid marriage, work and living as a family (Roberts et al., 2005). These universal social roles might also explain why the maturity effect has been observed in multiple cohorts and nations (Roberts et al., 2005).

The role of Self-transcendence as the most important predictor of personality change is noteworthy (Table 5). If Self-transcendence is associated with personal growth, as some studies have suggested (Staudinger \& Kunzmann, 2005), our findings can be interpreted to imply that personal growth facilitates personality change. It has been suggested that personal growth is associated with higher levels of personality development (Bauer \& McAdams, 2004). This would also mean that, paradoxically, young adults are not particularly well adjusted to the society (low SD and low CO) but their level of personal growth is rather high (high ST). Then, through complex developmental processes, people's adjustment level rises and their personal growth level lowers to meet the demands of cultural, role, and personal expectations.

\section{Possible causal mechanisms for personality change}

The largest changes in personality occur in young adulthood (age 20 - 40) but personality continues to change even in middle and old age, showing that personality traits can change at any age (Roberts \& Mroczek, 2008). In young adulthood people start a career, get married, and have children. In this time people shape their identities and choose the long-term goals in their lives (Roberts et al., 2006). These developmental tasks specific to young adulthood are one explanation for the observed changes in personality. 
Human development through the lifespan can be seen to be comprised of age- and stage-relevant tasks (Cicchetti \& Rogosch, 2002). Success in these tasks opens the possibility for positive development. Failure, however, might lead to maladaptive outcomes. In addition, major life changes and changes in social roles and contexts can affect mental health, and even predispose a person to psychopathology (Schulenberg, Sameroff, \& Cicchetti, 2004).

Through the life course, new developmental tasks arise and interact with the outcomes of prior developmental tasks. Human development can be seen as a dynamic process which is constantly open for change both for the good and for the bad (Cicchetti \& Rogosch, 2002). However, the longer a person's development follows a maladaptive path, the harder it is to return to a normal healthy developmental path (Cicchetti, 1993). The past has an impact on future development but negative life-events do not necessarily lead to maladaption and positive events to adaption: subsequent experience may alter the course of biological and psychological development and alter the effects of prior experience (Cicchetti \& Rogosch, 2002).

The effect of personality on behavior is not straightforward. The same level of one personality trait can lead to different behavioral outcomes in people depending on its interactions with other personality traits and the types of socializing environments (Frick \& Viding, 2009). Also, there are multiple developmental pathways to the same personality profile, and the effects of one environment variable (e.g., divorce) may be different between people (Cicchetti \& Richters, 1997). These empirical facts are usually referred to as the concepts of equifinality and multifinality (Cicchetti \& Rogosch, 1996). Equifinality states that people from different starting points can develop towards a common outcome (e.g, two adolescents with extremely high and low HA can be equally self-directed as adults). Multifinality means that people with similar backgrounds might develop towards different outcomes: of two children with low HA and high RD one might grow up to have low HA and 
high RD as an adult and the other high HA and low RD). A complex dynamic transaction of positive and negative processes determines the course of a person's development (Cicchetti \& Rogosch, 2002).

In general, developmental trends of personality (Agronick \& Duncan, 1998; Costa \& McCrae, 1982; Srivastava, John, Gosling, \& Potter, 2003) may be explained by factors that are unique to an individual (e.g., genes), the social climate in a society at a certain time, or generational differences (i.e., cohort effects). Such cohort effects can cause differences between people born in different years and environments; working-aged adults, for example, might be affected more by a nation-wide recession than retired adults.

Our results suggest that cultural norms, values, and expectations do not affect the mean-level of temperament traits (i.e., emotional responses) to the same extent as the character traits. It may be that cultural expectations are not related to what kind of emotions and in which situations one should feel but how one reacts and copes with one's emotions. According to this view, it is acceptable culturally for people to feel distressed or anxious as long as they can function normally and perform well in work, for example. Circumstances that require emotional self-regulation to achieve particular goals and express certain values are when being a mature person helps.

It is also possible that, with time, it has become more difficult to reach the definition of being successful and well-adjusted. High occupational and leisure time efficiency demands both require people to be highly self-directed and cooperative to be successful (Roberts \& Helson, 1997). Due to changes in the social climate, people work harder to reach these demands than before, and this is seen as the birth year effect in character. This view is supported by a study of first-year psychology student cohorts from 1982 to 2007 (Smits, Dolan, Vorst, Wicherts, \& Timmerman, 2011); results showed that the average maturity level of the first-year students increased in 25 years. This also means that, say, a five year period 
from age 20 to 25 may have different connotations for individuals from different birth cohorts due to changing external expectations and the work required to meet them.

According to a different formulation, there are at least two forces, a socialization effect and a selection effect, which can change the mean-level of personality traits (LodiSmith \& Roberts, 2007; Neyer \& Lehnart, 2007). Socialization effects refer to group conformity pressure that society exerts on an individual, including cultural norms, practices, values, and beliefs. Disciplinary actions for breaking these cultural expectations vary in accord with what behaviors are culturally regarded as desirable or unacceptable (Cicchetti \& Rogosch, 2002). For example, employees are expected to show up on time, work hard, and get along with coworkers. These expectations are similar to all employees and therefore they are assumed to affect personality change within individuals by punishing inappropriate behavior (eg., by withdrawal of rewards or by losing one's job) or rewarding appropriate behavior (Roberts et al., 2006). Consequently, social signals from other people and society can promote personality change by telling one how one should behave and change to meet expectations, meaning that environmental experiences affect personality functioning (Caspi et al., 2005).

Selection effects refer to a tendency for more mature people to invest more value in their social roles such as work, family and marriage (Lodi-Smith \& Roberts, 2007). Personality traits select people to have certain experiences and then these same traits are also the most influenced in response to those experiences, creating a feedback effect in selected individuals (Caspi et al., 2005; Jokela, Kivimaki, Elovainio, \& Keltikangas-Jarvinen, 2009). Based on the aforementioned effects it could also be predicted that a small sample of individuals growing up in isolation from society would not show the pattern of personality change towards maturity like that seen in most people (Donnellan et al., 2007). 
Our results showed that birth year affects character but not temperament. We suggest that this is due to a combination of socialization and selection effects. In Western cultures child-rearing generally aims at socializing children to be autonomous, independent, and responsible towards other people, which correspond to being self-directed and cooperative (Keller et al., 2006; Tulviste, Mizera, De Geer, \& Tryggvason, 2007). Furthermore, these same qualities help a person to have a successful marriage, career, and social relationships in the individuality-promoting Western cultures.

In the present study, the mean-level of three (HA, RD, PS) of the four temperament traits showed little or no change with age. The stability of Harm Avoidance in particular differs from the earlier results using the Big Five according to which emotional stability increases and negative emotionality gets lower with increasing age (e.g., McAdams \& Olson, 2010; Roberts et al., 2006). Our results suggest that general anxiety proneness (HA) remains stable with age while Self-directedness increases. It seems, in the light of our results, that with age people do learn to self-regulate their emotions (high SD) but the actual level of negative emotionality remains stable. We also found that Novelty Seeking decreased moderately with age. It is possible that repeated exposure to initially novel stimuli may lead to decreased Novelty Seeking. Thus, having experienced a wide variety of different stimuli may lower the number of sources with further novel stimuli which might lower Novelty Seeking since there is less novelty to be sought. Decreasing Novelty Seeking is in line with the Big Five related studies which have found a lower level of expression of internal impulses with age (McAdams \& Olson, 2010).

A very interesting result in the present study was the strong decrease of Selftranscendence with age. High Self-transcendence has previously been found to be associated with both negative and positive affect (Cloninger \& Zohar, 2011; Josefsson et al., 2011). People, who can see their lives as complex as they are really, are as likely to be happy as 
unhappy (Bauer \& McAdams, 2004). One explanation for this contradictory result is that being self-transcendent does improve one's well-being but, at the same time, the cultural secular norms may exert pressure to be less self-transcendent, which causes negative affect (Josefsson et al., 2011).

Another explanation is based on the different types of positive personality development and maturity. According to this view, Cooperativeness and Self-directedness measure adjustment to the society while Self-transcendence measures personal growth (Staudinger \& Kunzmann, 2005). Previous studies that have found declining personal growth with age support this view (Ryff, 1989; Ryff \& Keyes, 1995). Personal growth requires plenty of self-examination, motivation, and the right circumstances, which often make it a painful and difficult process. Furthermore, personal growth may not be necessary to be welladjusted to the society. Therefore, unlike developing Self-directedness and Cooperativeness, developing Self-transcendence is not constantly reinforced by the society and even if a person would like to grow towards greater Self-transcendence, finding out how to do that may be difficult. Thus, people focus their time and energy on more concrete goals of forming friendships, and having a successful marriage and career. All in all, people try to live, as they see it, good and happy lives. It may be that personal growth requires too much effort and contributes, according to a subjective evaluation, too little goodness and happiness to one's life to be a population-wide phenomenon. Consequently, the mean-level of Selftranscendence decreases with age as personal growth is not given the attention it needs.

\section{Methodological considerations}

A limitation of this study is that while temperament was measured three times, character was measured only twice. A third measurement would have been useful in clarifying further the 
developmental trends of the character traits. Also, women were somewhat overrepresented in all the measurement years which may introduce some bias to the population estimates.

\section{Conclusion}

The results of this study are in line with previous research which has found that personality develops towards greater maturity in adulthood. The most common course of development seems to be that with age people become more responsible and caring and more comfortable with themselves. Increasing Self-directedness and Cooperativeness with age in our study correspond closely to increasing agreeableness and conscientiousness observed in Big Five related studies (e.g., McAdams \& Olson, 2010; Roberts et al., 2006). Increasing emotional stability observed in Big Five -studies did not receive support from the present study since Harm Avoidance remained stable over time. Novelty Seeking decreased with age which is in line with increasing impulse-control observed in the Big Five-studies (McAdams \& Olson, 2010). We also observed a strongly decreasing age-trend for Self-transcendence which supports the previous findings of decreasing purpose in life and personal growth with age (Ryff, 1989; Ryff \& Keyes, 1995).

To our knowledge, this is the first population-based longitudinal study to examine the TCI-traits with more than two study waves and a time-span of more than a few years. Our Finnish study also broadens the cultural context of the TCI as most of these studies have been carried out in the United States. Furthermore, studying normal development is important to fully understand psychopathology and to identify abnormal development (Cicchetti \& Toth, 2009). Maturing with age seems to be the norm, and if a person shows a decrease in maturity, a serious concern should be raised concerning the well-being of that person. We have shown that as normal healthy people mature, they become more self-directed and cooperative. Overall, changes in temperament were comparatively smaller although Novelty Seeking and 
Reward Dependence decreased and Persistence slightly increased while the participants grew older.

In sum, we have shown the usefulness of the TCI personality model as the descriptor of personality development within an individual over time. The TCI is a valuable tool in understanding and describing the genetic, neurobiological, social, and psychological effects that make us who we are. Moreover, the psychobiological theory postulates that differences between temperament-related procedural learning and character related propositional learning should lead to qualitative differences between the development of temperament and character (Cloninger, 2003; Cloninger, 2004; Cloninger, 2008). Indeed, we have shown that there are qualitative differences between the development of temperament and character. Character and temperament may correlate moderately at one time point but they show qualitatively distinct developmental patterns. Furthermore, birth cohorts differ on the mean-levels of the character traits but not on the temperament traits. This qualitative information would be lost if temperament and character were combined and not treated as distinct domains. 


\section{References}

Agronick, G. S., \& Duncan, L. E. (1998). Personality and social change: Individual differences, life path, and importance attributed to the women's movement. Journal of Personality and Social Psychology, 74(6), 1545-1555.

Allport, G. W. (1951). Personality: A psychological interpretation. London: Constable \& Company ltd.

Allport, G. W. (1961). Pattern and growth in personality. New York: Holt, Rinehart \& Winston.

Andersson, J. O. (2008). Finland - twelve points! Research on Finnish Society, 1(1), 59-69.

Bauer, J., \& McAdams, D. (2004). Growth goals, maturity, and well-being. Developmental Psychology, 40(1), 114-127.

Block, J. (1995). A contrarian view of the 5-factor approach to personality description. Psychological Bulletin, 117(2), 187-215.

Carlin, J. B., Gurrin, L. C., Sterne, J. A. C., Morley, R., \& Dwyer, T. (2005). Regression models for twin studies: A critical review. International Journal of Epidemiology, 34(5), 1089-1099.

Caspi, A., Roberts, B. W., \& Shiner, R. L. (2005). Personality development: Stability and change. Annual Review of Psychology, 56, 453-484. 
Cicchetti, D., \& Richters, J. E. (1997). Examining the conceptual and scientific underpinnings of research in developmental psychopathology. Development and Psychopathology, 9(2), 189-191.

Cicchetti, D., \& Rogosch, F. A. (1996). Equifinality and multifinality in developmental psychopathology. Development and Psychopathology, 8(4), 597-600.

Cicchetti, D., \& Rogosch, F. A. (2002). A developmental psychopathology perspective on adolescence. Journal of Consulting and Clinical Psychology, 70(1), 6-20.

Cicchetti, D. (1993). Developmental psychopathology: Reactions, reflections, projections. Developmental Review, 13(4), 471-502.

Cicchetti, D., \& Toth, S. L. (2009). The past achievements and future promises of developmental psychopathology: The coming of age of a discipline. Journal of Child Psychology and Psychiatry, 50(1-2), 16-25.

Cloninger, C. R. (1987). A systematic method for clinical description and classification of personality variants - a proposal. Archives of General Psychiatry, 44(6), 573-588.

Cloninger, C. R. (2003). Completing the psychobiological architecture of human personality development: Temperament, character \& coherence. In U. M. Staudinger, \& U. E. R. Lindenberger (Eds.), Understanding human development: Dialogues with lifespan psychology (pp. 159-182). Boston: Kluwer Academic Publishers.

Cloninger, C. R. (2004). Feeling good. the science of well-being. New York: Oxford University Press Inc. 
Cloninger, C. R. (2006). Personality as a dynamic psychobiological system. In T. A. Widiger, E. Simonsen, P. J. Sirovatka \& D. A. Regier (Eds.), Dimensional models of personality disorders: Refining the research agenda for DSM-V (pp. 73-76). Washington D.C: American Psychiatric Press.

Cloninger, C. R., Przybeck, T. R., Svrakic, D. M., \& Wetzel, R. D. (1994). The temperament and character inventory (TCI): A guide to its development and use. St Louis: Washington University Center for Psychobiology of Personality.

Cloninger, C. R., Svrakic, N. M., \& Svrakic, D. M. (1997). Role of personality selforganization in development of mental order and disorder. Development and Psychopathology, 9(4), 881-906.

Cloninger, C. R., Zohar, A. H., \& Cloninger, K. M. (2010). Promotion of well-being in person-centered mental health care. Focus, 8(2), 165-179.

Cloninger, C. R. (2008). The psychobiological theory of temperament and character: Comment on farmer and goldberg (2008). Psychological Assessment, 20(3), 292-299.

Cloninger, C. R. (2010). Personality and temperament: New and alterntive perspectives. Focus, 8(2), 161-163.

Cloninger, C. R., Bayon, C., \& Svrakic, D. M. (1998). Measurement of temperament and character in mood disorders: A model of fundamental states as personality types. Journal of Affective Disorders, 51(1), 21-32.

Cloninger, C. R., Svrakic, D. M., \& Przybeck, T. R. (1993). A psychobiological model of temperament and character. Archives of General Psychiatry, 50(12), 975-990. 
Cloninger, C. R., Svrakic, D. M., \& Przybeck, T. R. (2006). Can personality assessment predict future depression? A twelve-month follow-up of 631 subjects. Journal of Affective Disorders, 92(1), 35-44.

Cloninger, C. R., \& Zohar, A. H. (2011). Personality and the perception of health and happiness. Journal of Affective Disorders, 128(1-2), 24-32.

Cloninger, C. R., Zohar, A. H., Hirschmann, S., \& Dahan, D. The psychological costs and benefits of being highly persistent: Personality profiles distinguish mood disorders from anxiety disorders. Journal of Affective Disorders, In press.

Costa, P. T., \& Mccrae, R. R. (1982). An approach to the attribution of aging, period, and cohort effects. Psychological Bulletin, 92(1), 238-250.

Coward, D. D., \& Reed, P. G. (1996). Self-transcendence: A resource for healing at the end of life. Issues in Mental Health Nursing, 17(3), 275-288.

Donnellan, M. B., Conger, R. D., \& Burzette, R. G. (2007). Personality development from late adolescence to young adulthood: Differential stability, normative maturity, and evidence for the maturity-stability hypothesis. Journal of Personality, 75(2), 237-263.

Donnellan, M. B., \& Trzesniewski, K. H. (2010). Groundhog day versus alice in wonderland, red herrings versus swedish fishes, and hopefully something constructive: A reply to comments. Perspectives on Psychological Science, 5(1), 103-108.

Farmer, R. F., \& Goldberg, L. R. (2008a). Brain modules, personality layers, planes of being, spiral structures, and the equally implausible distinction between TCI-R "temperament" and "character" scales: Reply to Cloninger (2008). Psychological Assessment, 20(3), 300-304. 
Farmer, R. F., \& Goldberg, L. R. (2008b). A psychometric evaluation of the revised temperament and character inventory (TCI-R) and the TCI-140. Psychological Assessment, 20(3), 281-291.

Ferguson, C. J. (2010). A meta-analysis of normal and disordered personality across the life span. Journal of Personality and Social Psychology, 98(4), 659-667.

Frick, P. J., \& Viding, E. (2009). Antisocial behavior from a developmental psychopathology perspective. Development and Psychopathology, 21(4), 1111-1131.

Gillespie, N. A., Cloninger, C. R., Heath, A. C., \& Martin, N. G. (2003). The genetic and environmental relationship between Cloninger's dimensions of temperament and character. Personality and Individual Differences, 35(8), 1931-1946.

Hansenne, M., Delhez, M., \& Cloninger, C. R. (2005). Psychometric properties of the temperament and character inventory-revised (TCI-R) in a Belgian sample. Journal of Personality Assessment, 85(1), 40-49.

Heath, A. C., Cloninger, C. R., \& Martin, N. G. (1994). Testing a model for the geneticstructure of personality - a comparison of the personality systems of Cloninger and Eysenck. Journal of Personality and Social Psychology, 66(4), 762-775.

Helson, R., \& Wink, P. (1987). 2 conceptions of maturity examined in the findings of a longitudinal-study. Journal of Personality and Social Psychology, 53(3), 531-541.

Herbst, J. H., Zonderman, A. B., McCrae, R. R., \& Costa, P. T. (2000). Do the dimensions of the temperament and character inventory map a simple genetic architecture? Evidence from molecular genetics and factor analysis. American Journal of Psychiatry, 157(8), $1285-1290$. 
Hogan, R., \& Roberts, B. W. (2004). A socioanalytic model of maturity. Journal of Career Assessment, 12(2), 207-217.

Hopwood, C. J., Donnellan, M. B., Blonigen, D. M., Krueger, R. F., McGue, M., Iacono, W. G., et al. (2011). Genetic and environmental influences on personality trait stability and growth during the transition to adulthood: A three-wave longitudinal study. Journal of Personality and Social Psychology, 100(3), 545-556.

Jokela, M., Hintsa, T., Hintsanen, M., \& Keltikangas-Jarvinen, L. (2010). Adult temperament and childbearing over the life course. European Journal of Personality, 24(2), 151-166.

Jokela, M., Kivimaeki, M., Elovainio, M., \& Keltikangas-Jaervinen, L. (2009). Personality and having children: A two-way relationship. Journal of Personality and Social Psychology, 96(1), 218-230.

Josefsson, K., Cloninger, C. R., Hintsanen, M., Jokela, M., Pulkki-Råback, L., \& Keltikangas-Järvinen, L. (2011). Associations of personality profiles with various aspects of well-being: A population-based study. Journal of Affective Disorders, 133(12), 265-273.

Kääriäinen, K., Ketola, K., Niemelä, K., Palmu, H., \& Salomäki, H. (2009). Facing diversity: The Evangelical Lutheran church of Finland from 2004 to 2007. Tampere: Church Research Institute.

Keller, H., Lamm, B., Abels, M., Yovsi, R., Borke, J., Jensen, H., et al. (2006). Cultural models, socialization goals, and parenting ethnotheories. Journal of Cross-Cultural Psychology, 37(2), 155-172. 
Klimstra, T. A., Hale,William W.,,III, Raaijmakers, A. W., Branje, S. J. T., \& Meeus, W. H. J. (2009). Maturation of personality in adolescence. Journal of Personality and Social Psychology, 96(4), 898-912.

Lodi-Smith, J., \& Roberts, B. W. (2007). Social investment and personality: A meta-analysis of the relationship of personality traits to investment in work, family, religion, and volunteerism. Personality and Social Psychology Review, 11(1), 68-86.

Lucas, R. E., \& Donnellan, M. B. (2011). Personality development across the life span: Longitudinal analyses with a national sample from germany. Journal of Personality and Social Psychology, 101(4), 847-861.

Luedtke, O., Roberts, B. W., Trautwein, U., \& Nagy, G. (2011). A random walk down university avenue: Life paths, life events, and personality trait change at the transition to university life. Journal of Personality and Social Psychology, 101(3), 620-637.

Maitland, S. B., Nyberg, L., Bäckman, L., Nilsson, L., \& Adolfsson, R. (2009). On the structure of personality: Are there separate temperament and character factors? Personality and Individual Differences, 47(3), 180-184.

Martinotti, G., Mandelli, L., Di Nicola, M., Serretti, A., Fossati, A., Borroni, S., et al. (2008). Psychometric characteristic of the Italian version of the temperament and character inventory - revised, Personality, psychopathology, and attachment styles. Comprehensive Psychiatry, 49(5), 514-522.

McAdams, D. P., \& Olson, B. D. (2010). Personality development: Continuity and change over the life course. Annual Review of Psychology, 61, 517-542. 
Mulder, R. T., \& Joyce, P. R. (1997). Temperament and the structure of personality disorder symptoms. Psychological Medicine, 27(1), 99-106.

Neyer, F. J., \& Lehnart, J. (2007). Relationships matter in personality development: Evidence from an 8-year longitudinal study across young adulthood. Journal of Personality, 75(3), 535-568.

Ojala, M. (2000). Parent and teacher expectations for developing young children: A crosscultural comparison between Ireland and Finland. European Early Childhood Education Research Journal, 8(2), 39-61.

Pelissolo, A., Mallet, L., Baleyte, J. M., Michel, G., Cloninger, C. R., Allilaire, J. F., et al. (2005). The temperament and character inventory-revised (TCI-R): Psychometric characteristics of the French version. Acta Psychiatrica Scandinavica, 112(2), 126-133.

Raitakari, O. T., Juonala, M., Ronnemaa, T., Keltikangas-Jarvinen, L., Rasanen, L., Pietikainen, M., et al. (2008). Cohort profile: The cardiovascular risk in young Finns study. International Journal of Epidemiology, 37(6), 1220-1226.

Roberts, B. W., Caspi, A., \& Moffitt, T. E. (2001). The kids are alright: Growth and stability in personality development from adolescence to adulthood. Journal of Personality and Social Psychology, 81(4), 670-683.

Roberts, B. W., \& Helson, R. (1997). Changes in culture, changes in personality: The influence of individualism in a longitudinal study of women. Journal of Personality and Social Psychology, 72(3), 641-651. 
Roberts, B. W., Walton, K. E., \& Viechtbauer, W. (2006). Patterns of mean-level change in personality traits across the life course: A meta-analysis of longitudinal studies. Psychological Bulletin, 132(1), 1-25.

Roberts, B. W., \& DelVecchio, W. F. (2000). The rank-order consistency of personality traits from childhood to old age: A quantitative review of longitudinal studies. Psychological Bulletin, 126(1), 3-25.

Roberts, B. W., \& Mroczek, D. (2008). Personality trait change in adulthood. Current Directions in Psychological Science, 17(1), 31-35.

Roberts, B. W., Wood, D., \& Caspi, A. (2008). The development of personality traits in adulthood. In O. P. John, R. W. Robins \& L. A. Pervin (Eds.), Handbook of personality: Theory and research (3rd ed., pp. 375-398). New York: The Guilford Press.

Roberts, B. W., Wood, D., \& Smith, J. L. (2005). Evaluating Five Factor Theory and social investment perspectives on personality trait development. Journal of Research in Personality, 39(1), 166-184.

Ryff, C. D. (1989). Happiness is everything, or is it - explorations on the meaning of psychological well-being. Journal of Personality and Social Psychology, 57(6), 10691081.

Ryff, C. D. (1991). Possible selves in adulthood and old-age - a tale of shifting horizons. Psychology and Aging, 6(2), 286-295.

Ryff, C. D., \& Keyes, C. L. M. (1995). The structure of psychological well-being revisited. Journal of Personality and Social Psychology, 69(4), 719-727. 
Schulenberg, J. E., Sameroff, A. J., \& Cicchetti, D. (2004). The transition to adulthood as a critical juncture in the course of psychopathology and mental health. Development and Psychopathology, 16(4), 799-806.

Smits, I. A. M., Dolan, C. V., Vorst, H. C. M., Wicherts, J. M., \& Timmerman, M. E. (2011). Cohort differences in big five personality factors over a period of 25 years. Journal of Personality and Social Psychology, 100(6), 1124-1138.

Soto, C. J., John, O. P., Gosling, S. D., \& Potter, J. (2011). Age differences in personality traits from 10 to 65: Big five domains and facets in a large cross-sectional sample. Journal of Personality and Social Psychology, 100(2), 330-348.

Specht, J., Egloff, B., \& Schmukle, S. C. (2011). Stability and change of personality across the life course: The impact of age and major life events on mean-level and rank-order stability of the Big Five. Journal of Personality and Social Psychology, 101(4), 862882.

Srivastava, S., John, O., Gosling, S., \& Potter, J. (2003). Development of personality in early and middle adulthood: Set like plaster or persistent change? Journal of Personality and Social Psychology, 84(5), 1041-1053.

Stallings, M. C., Hewitt, J. K., Cloninger, C. R., Heath, A. C., \& Eaves, L. J. (1996). Genetic and environmental structure of the Tridimensional Personality Questionnaire: Three or four temperament dimensions? Journal of Personality and Social Psychology, 70(1), 127-140.

Staudinger, U. M., \& Kunzmann, U. (2005). Positive adult personality development adjustment and/or growth? European Psychologist, 10(4), 320-329. 
Svrakic, D. M., Whitehead, C., Przybeck, T. R., \& Cloninger, C. R. (1993). Differentialdiagnosis of personality-disorders by the 7-factor model of temperament and character. Archives of General Psychiatry, 50(12), 991-999.

Terracciano, A., Costa, P. T., Jr., \& McCrae, R. R. (2006). Personality plasticity after age 30. Personality and Social Psychology Bulletin, 32(8), 999-1009.

Trouillet, R., \& Gana, K. (2008). Age differences in temperament, character and depressive mood: A cross-sectional study. Clinical Psychology \& Psychotherapy, 15(4), 266-275.

Tulviste, T., Mizera, L., De Geer, B., \& Tryggvason, M. (2007). Child-rearing goals of Estonian, Finnish, and Swedish mothers. Scandinavian Journal of Psychology, 48(6), 487-497. 


\section{Figure Captions}

Figure 1. Population z-scores plotted against age group for temperament traits. Scores are standardized to the mean and standard deviation of the 20 -year olds. $95 \%$ confidence intervals included. Results based on a multilevel model.

Figure 2. Population z-scores plotted against age group for character traits. Scores are standardized to the mean and standard deviation of the 20 -year olds. $95 \%$ confidence intervals included. Results based on a multilevel model. 
Table 1

Means and standard deviations of the TCI personality traits in men and women

\begin{tabular}{|c|c|c|c|c|c|c|c|c|c|c|c|c|c|c|c|}
\hline \multirow[b]{3}{*}{ TCI traits } & \multicolumn{5}{|c|}{ Year 1997} & \multicolumn{5}{|c|}{ Year 2001} & \multicolumn{5}{|c|}{ Year 2007} \\
\hline & \multicolumn{2}{|l|}{ Men } & \multicolumn{2}{|c|}{ Women } & \multirow[t]{2}{*}{$\mathrm{p}$} & \multicolumn{2}{|l|}{ Men } & \multicolumn{2}{|c|}{ Women } & \multirow[t]{2}{*}{$\mathrm{p}$} & \multicolumn{2}{|l|}{ Men } & \multicolumn{2}{|c|}{ Women } & \multirow[t]{2}{*}{$\mathrm{p}$} \\
\hline & $\mathrm{M}$ & SD & $\bar{M}$ & SD & & $\bar{M}$ & SD & $\overline{\mathrm{M}}$ & SD & & $\bar{M}$ & SD & $\mathrm{M}$ & SD & \\
\hline Novelty Seeking & 3.01 & 0.40 & 3.09 & 0.42 & $<.01$ & 2.94 & 0.40 & 3.03 & 0.42 & $<.01$ & 2.90 & 0.38 & 2.95 & 0.40 & $<.01$ \\
\hline Harm Avoidance & 2.55 & 0.51 & 2.72 & 0.54 & $<.01$ & 2.52 & 0.52 & 2.73 & 0.54 & $<.01$ & 2.54 & 0.51 & 2.73 & 0.53 & $<.01$ \\
\hline Reward Dependence & 3.16 & 0.41 & 3.47 & 0.40 & $<.01$ & 3.16 & 0.41 & 3.52 & 0.41 & $<.01$ & 3.12 & 0.40 & 3.48 & 0.40 & $<.01$ \\
\hline Persistence & 3.24 & 0.53 & 3.20 & 0.57 & .07 & 3.21 & 0.53 & 3.21 & 0.57 & .90 & 3.24 & 0.53 & 3.27 & 0.56 & .19 \\
\hline Self-directedness & 3.58 & 0.44 & 3.56 & 0.44 & .36 & 3.69 & 0.43 & 3.66 & 0.44 & .13 & & & & & \\
\hline Cooperativeness & 3.59 & 0.44 & 3.77 & 0.40 & $<.01$ & 3.66 & 0.42 & 3.84 & 0.39 & $<.01$ & & & & & \\
\hline Self-transcendence & 2.46 & 0.53 & 2.70 & 0.54 & $<.01$ & 2.33 & 0.53 & 2.60 & 0.56 & $<.01$ & & & & & \\
\hline
\end{tabular}

Note. Values based on average scores on a 5-point Likert scale

P-values for t-tests testing for the difference in means between men and women included

Number of participants: 1997: $n=2104(n(m e n)=841,40 \%, n($ women $)=1263,60 \%), 2001: n=2095(n(m e n)=881,42 \%, n($ women $)=1214,58 \%)$, 
2007: $\mathrm{n}=2056(\mathrm{n}(\mathrm{men})=845,41 \%, \mathrm{n}($ women $)=1211,59 \%)$ 
Table 2

Correlations of the TCI traits over 4, 6, and 10 years of follow-up

\begin{tabular}{|c|c|c|c|}
\hline & 4 years $(1997-2001)$ & 6 years $(2001-2007)$ & 10 years $(1997-2007)$ \\
\hline & $\mathrm{n}=1580$ & $\mathrm{n}=1643$ & $\mathrm{n}=1546$ \\
\hline Novelty Seeking & 77 & 78 & 70 \\
\hline Age $20-26$ & $75^{\mathrm{a}}$ & 76 & $67^{\mathrm{a}}$ \\
\hline Age $29-35$ & $79^{a}$ & 79 & $73^{a}$ \\
\hline Harm Avoidance & 78 & 80 & 71 \\
\hline Age $20-26$ & $75^{\mathrm{a}}$ & $78^{\mathrm{a}}$ & 70 \\
\hline Age $29-35$ & $81^{\mathrm{a}}$ & $82^{\mathrm{a}}$ & 73 \\
\hline \multicolumn{4}{|l|}{ Reward } \\
\hline Dependence & 75 & 76 & 68 \\
\hline Age $20-26$ & 73 & 75 & 67 \\
\hline Age $29-35$ & 77 & 76 & 70 \\
\hline Persistence & 63 & 67 & 57 \\
\hline Age $20-26$ & 61 & 68 & 54 \\
\hline Age $29-35$ & 66 & 67 & 60 \\
\hline Self-directedness & 73 & - & - \\
\hline Age $20-26$ & 71 & & \\
\hline Age $29-35$ & 75 & & \\
\hline Cooperativeness & 73 & - & - \\
\hline Age $20-26$ & 71 & & \\
\hline Age $29-35$ & 75 & & \\
\hline Self-transcendence & 77 & - & - \\
\hline
\end{tabular}


Age $20-26 \quad 76$

Age $29-35 \quad 78$

Note. Values are correlation coefficients multiplied by 100 ( $\mathrm{r} \times 100)$ for all participants and for two age groups

All correlations are significant at $p<0.01$

Age $=$ age in year 1997

${ }^{a}$ correlations of age groups 20-26 and 29-35 differ significantly 
Table 3

Mean-level change of the TCI-traits using age as a continuous dependent variable

\begin{tabular}{|c|c|c|c|c|c|c|c|c|c|}
\hline \multirow[b]{2}{*}{ TCI-trait } & \multicolumn{3}{|c|}{ Total regression } & \multicolumn{3}{|c|}{ Within regression } & \multicolumn{3}{|c|}{ Between regression } \\
\hline & $\bar{B}$ & $\mathrm{SE}$ & $\mathrm{p}$ & $\bar{B}$ & SE & $\mathrm{p}$ & $\bar{B}$ & SE & $\mathrm{p}$ \\
\hline Novelty Seeking & -0.22 & .02 & $<.01$ & -0.22 & .02 & $<.01$ & -0.22 & .03 & $<.01$ \\
\hline Harm Avoidance & 0.00 & .02 & .81 & 0.00 & .02 & .88 & 0.02 & .03 & .47 \\
\hline Reward Dependence & -0.07 & .02 & $<.01$ & -0.07 & .02 & $<.01$ & -0.06 & .03 & .06 \\
\hline Persistence & 0.06 & .02 & $<.01$ & 0.10 & .02 & $<.01$ & -0.02 & .03 & .52 \\
\hline Self-directedness & 0.34 & .03 & $<.01$ & 0.58 & .04 & $<.01$ & 0.20 & .04 & $<.01$ \\
\hline Cooperativeness & 0.20 & .03 & $<.01$ & 0.33 & .04 & $<.01$ & 0.13 & .03 & $<.01$ \\
\hline Self-transcendence & -0.25 & .03 & $<.01$ & -0.52 & .04 & $<.01$ & -0.07 & .04 & .04 \\
\hline
\end{tabular}

Note. Trait scores were standardized to the mean and standard deviation of the 20-year olds $\mathrm{B}=$ mean-level change on a given trait in standard deviations in 10 years

Based on a multilevel model (generalized estimating equations). Sex was controlled in all the analyses

In the within-individual regressions, mean-level differences between individuals have been removed by examining how repeated measurements from the same individual differ from the individual's mean level of the trait. Between-individual regressions compare mean-level differences between individuals by averaging over the repeated measurements within individuals. Total (ordinary) regressions are weighted average of the within-individual and between-individual regressions. See Methods for statistical details. 
Table 4

The effect of birth year on the mean levels of temperament and character traits

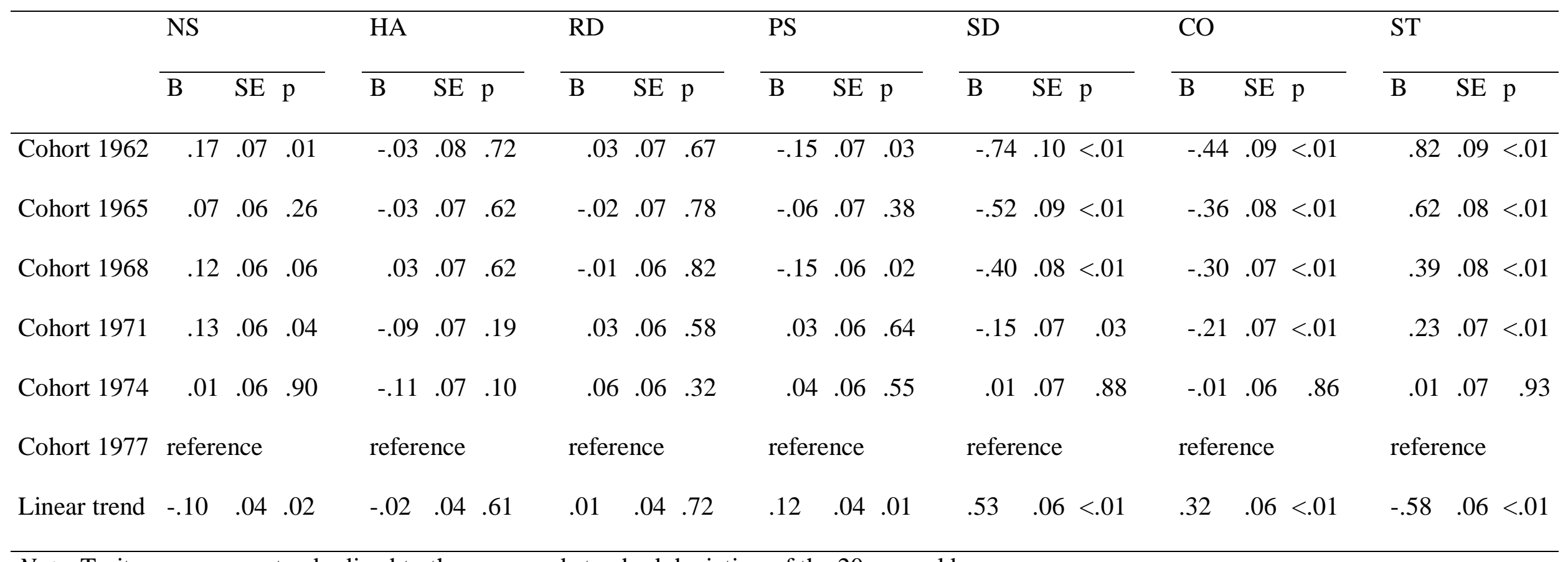

Note. Trait scores were standardized to the mean and standard deviation of the 20-year olds

Based on a multilevel model. Age and sex were controlled.

Linear trend $=$ the effect of a 10-year increase in birth year in standard deviations

NS=Novelty Seeking, HA=Harm Avoidance, RD=Reward Dependence, PS=Persistence, SD=Self-directedness, CO=Cooperativeness, ST=Self- 
transcendence 
Table 5

Traits scores in 1997 predicting the total change of all the TCI traits, character traits, and temperament traits from year 1997 to 2001

\begin{tabular}{|c|c|c|c|c|c|c|c|c|c|}
\hline \multirow[b]{2}{*}{ TCI-trait } & \multicolumn{3}{|c|}{ All traits } & \multicolumn{3}{|c|}{ Character } & \multicolumn{3}{|c|}{ Temperament } \\
\hline & $\bar{B}$ & $\mathrm{SE}$ & $\mathrm{p}$ & $\bar{B}$ & $\mathrm{SE}$ & $\mathrm{p}$ & B & $\mathrm{SE}$ & $\mathrm{p}$ \\
\hline Novelty Seeking & .09 & .02 & $<.01$ & .06 & .02 & $<.01$ & .06 & .02 & $<.01$ \\
\hline Harm Avoidance & .00 & .02 & .90 & .01 & .02 & .75 & -.01 & .02 & .60 \\
\hline Reward Dependence & -.01 & .02 & .59 & .00 & .02 & .81 & .00 & .02 & .44 \\
\hline Persistence & .05 & .02 & .01 & .03 & .02 & .04 & .03 & .02 & .03 \\
\hline Self-directedness & -.05 & .02 & $<.01$ & -.08 & .02 & $<.01$ & .00 & .02 & .91 \\
\hline Cooperativeness & -.01 & .02 & .61 & -.05 & .02 & $<.01$ & .03 & .02 & .10 \\
\hline Self-transcendence & .11 & .02 & $<.01$ & .11 & .02 & $<.01$ & .05 & .02 & $<.01$ \\
\hline
\end{tabular}

Note. $\mathrm{B}=$ total change in standard deviations per one standard deviation difference on a given trait

Age was controlled

Total change defined as the Euclidean distance (see Methods) which is always positive. 

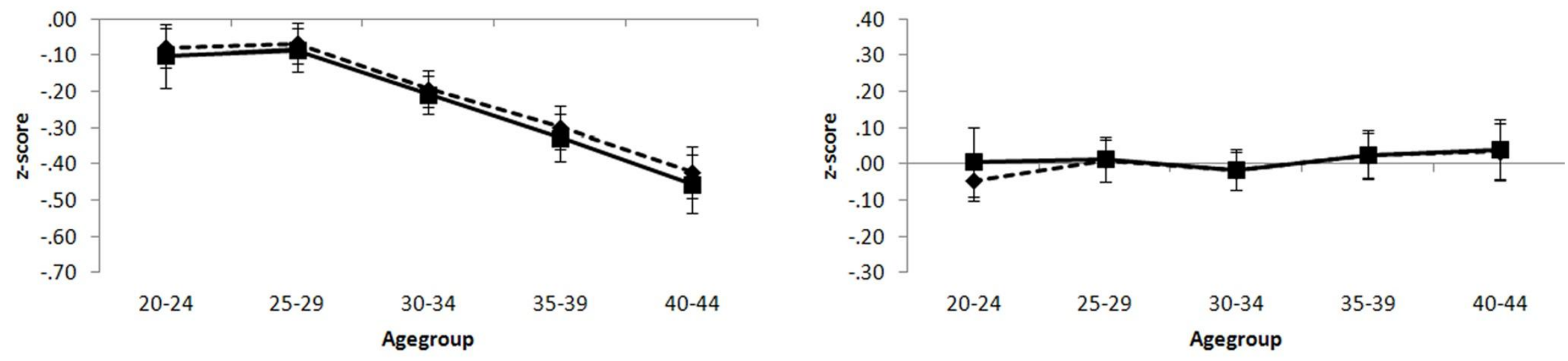

$-\not-$ Novelty Seeking, sex controlled

$-\not-$ Harm Avoidance, sex controlled

$\rightarrow$ Novelty Seeking, sex and birth year controlled

$\rightarrow$ Harm Avoidance, sex and birth year controlled
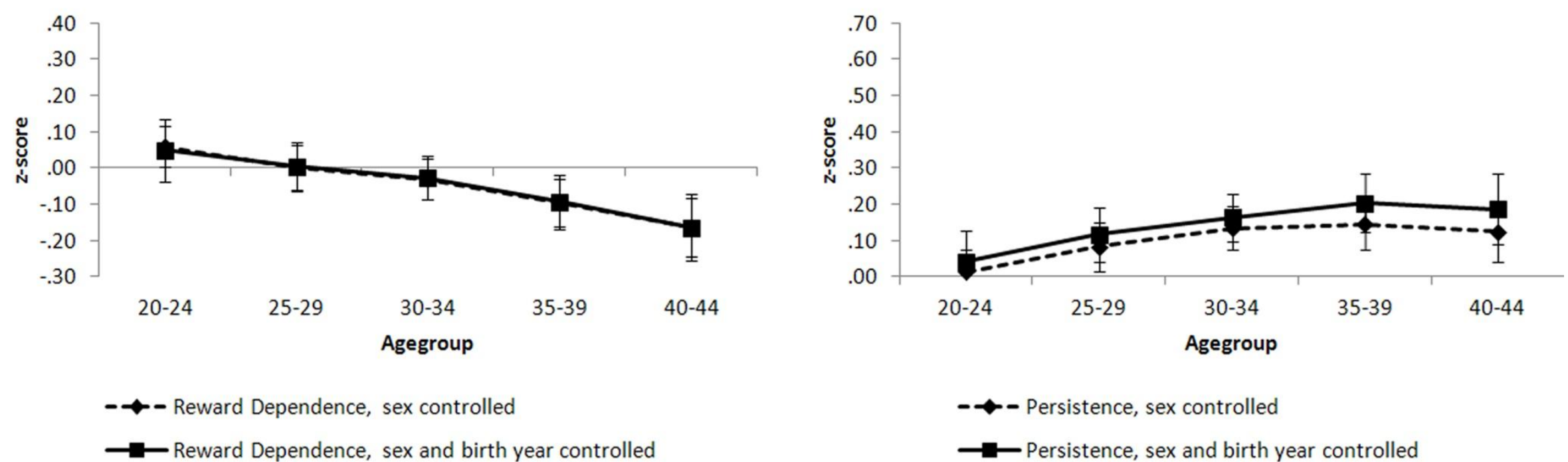

Figure 1 


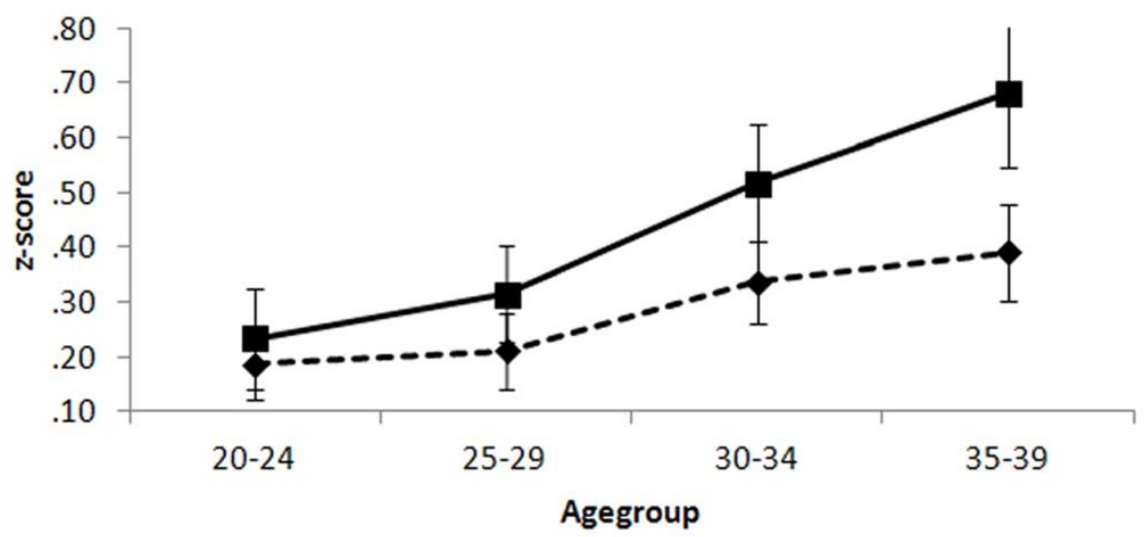

$-\not \neg-$ Self-directedness, sex controlled

$\rightarrow$-Self-directedness, sex and birth year controlled

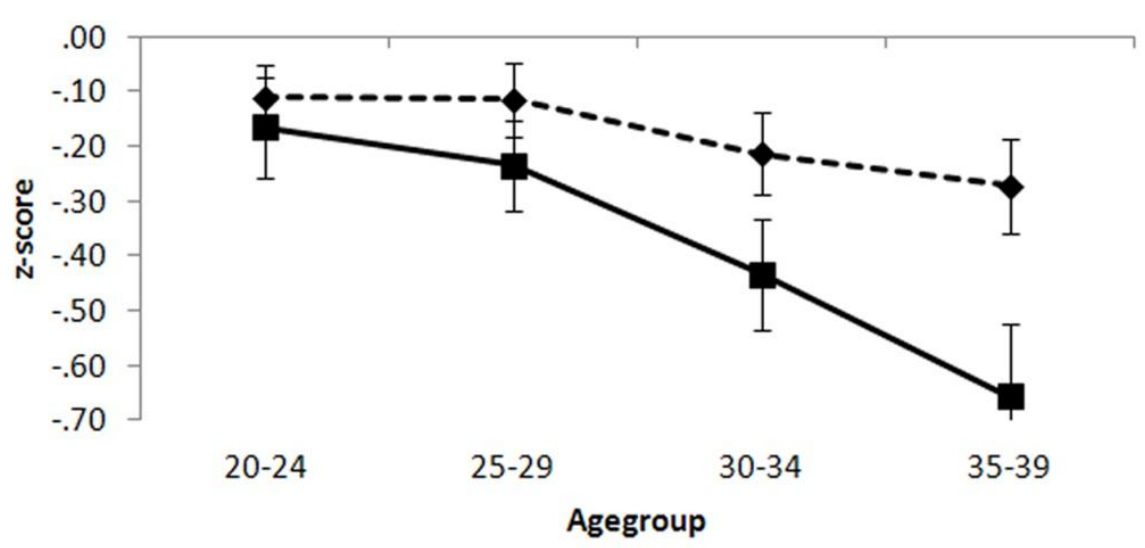

$-\not-$ - Self-transcendence, sex controlled

$\rightarrow$ Self-transcendence, sex and birth year controlled

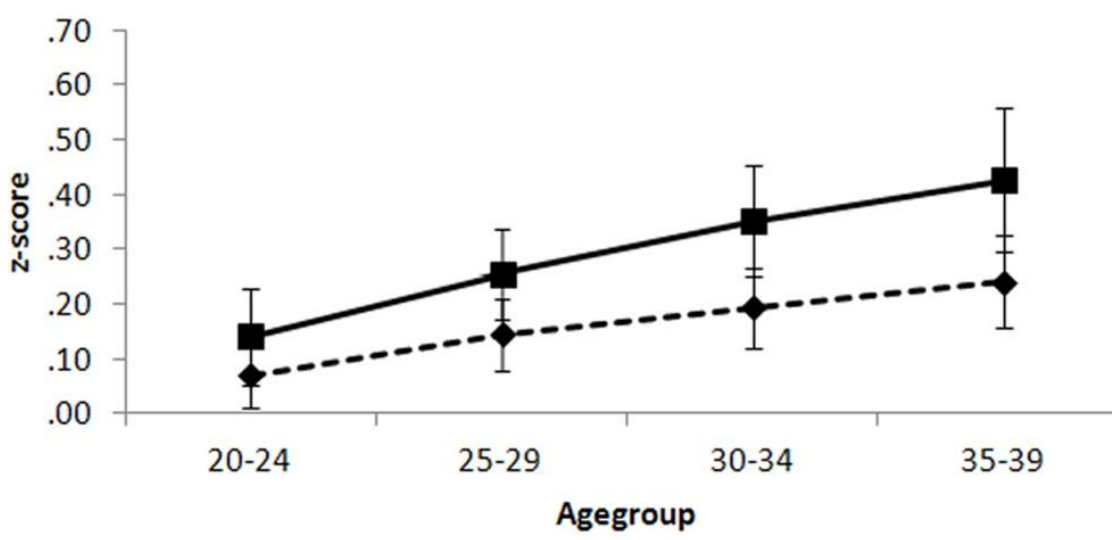

$-\not-$ Cooperativeness, sex controlled

$\rightarrow$ Cooperativeness, sex and birth year controlled

\section{Figure 2}


Temperament and character 53 